\title{
Trabalho e Acidentes no Meio Rural do Oeste Catarinense Santa Catarina, Brasil
}

Sandra Márcia Tietz Marques'

Glades Pinheiro da Silva'

\section{Agricultural Work-Related Accidents in the West of Santa Catarina, Brazil}

'Departamento Técnico de Produção e Extensão da Escola Agrotécnica Federal de Concórdia, Santa Catarina, Brasil.
Este estudo objetivou verificar a ocorrência de acidentes e características do trabalhador rural do Oeste de Santa Catarina, Brasil. Foram utilizados 60 questionários padronizados, com dados sociodemográficos, de trabalho e acidente laboral. Predominam os chefes de família (60\%), com idade entre 41 e 60 anos e os casados (68,3\%), com escolaridade média entre 4 a 8 anos, sendo $97 \%$ de famílias proprietárias, com área rural acima de 8 hectares representando $83,3 \%$. A jornada semanal de trabalho de $80 \%$ dos trabalhadores rurais ultrapassa 40 horas semanais, com $20 \%$ de ocorrência de acidentes. Os dados revelam a diversidade de atividades e de riscos ocupacionais e alertam para a urgência na abordagem da vigilância em saúde pública, onde os acidentes de trabalho no meio rural estão a merecer atenção nas políticas sociais brasileiras, além de não participarem das estatísticas oficiais do país.

Palavras-chaves Acidente Laboral, Trabalhadores Rurais, Saúde Ocupacional.

The aim of the present study was to check the characteristics of agricultural workers and the incidence of work-related accidents in the west of Santa Catarina, Brazil. Sixty patterned questionnaires were used, and data on sociodemographics, work, and workplace accidents were collected. The percentage of household heads aged between 41 and 60 years amounted to $60 \%$ and that of married ones totaled $68.3 \%$, with average school attendance between 4 and 8 years; $97 \%$ were landowners, among whom $83.3 \%$ owned more than 8 hectares. The average weekly workload of $80 \%$ of agricultural workers exceeds 40 hours, with a $20 \%$ incidence of workplace accidents. These data show the variety of activities and occupational hazards and point out an urgent need for public health surveillance, since accidents involving agricultural workers usually do not appear in the official statistics and still have to be addressed by Brazilian social policies.

Keywords Workplace Accidents, Agricultural Workers, Occupational Health. 


\section{Introdução}

No Brasil, a realidade dos acidentes de trabalho é limitada à Previdência Social e abrange trabalhadores com carteira assinada, que representam menos da metade da força de trabalho atuante ${ }^{7}$. Estudos de base populacional sobre a ocorrência de acidentes de trabalho rural não são freqüentes.

Acidente de trabalho é a ocorrência imprevista e indesejável, instantânea ou não, relacionada ao exercício do trabalho, que provoca lesão pessoal ou de que decorre risco próximo ou remoto de lesão. Todavia esta conceituação se aplica apenas às notificações para a Previdência ${ }^{2}$.

Entre os fatores de risco, $50 \%$ a $70 \%$ dos trabalhadores estão expostos a fatores ergonômicos, biológicos, físicos, químicos e psicossociais e mais de $60 \%$ são expostos a cargas de trabalho ou à condição ergonômica deficiente no trabalho. É estimado que $80 \%$ dos trabalhadores são expostos a ruídos, vibrações, radiações iônicas, eletromagnéticas e a microclimas insalubres no local de trabaIho. A exposição a diversos fatores de riscos biológicos acarreta problemas em distintos grupos de trabalhadores. Os fatores de risco psicossociais como condições sociais no trabalho, desigualdade e injustiça, instabilidade econômica e perspectiva com atividade laboral são elementos influentes na rotina de trabalho e podem ser desencadeantes de condições inseguras $9,11,12$.

Os trabalhadores rurais estão constantemente expostos a agentes causadores de agravos à saúde, como máquinas e equipamentos agrícolas, ferramentas manuais, agrotóxicos, animais domésticos e peçonhentos, exposição a agentes microbianos, vacinas e produtos terapêuticos na produção animal' .

Embora a utilização de máquinas e equipamentos seja rotina, a maioria dos trabaIhadores rurais não utiliza equipamentos de proteção individual, o que predispõe ao maior risco de acidentes. Além disso, nas propriedades rurais o aprendizado das tarefas é passado, via de regra, de uma geração à outra desde a infância e o conhecimento de sua utilização e o treinamento técnico inadequado também colaboram para aumentar o risco de acidentes ${ }^{12}$.

No Brasil, não existem informações preci- sas sobre o número de acidentes que ocorrem pelo exercício do trabalho. Estimativas dão conta que ocorrem anualmente, no Brasil, cerca de 3 milhões de acidentes com trabalhadores $^{3}$. Na zona rural a situação é bem mais grave, pois as pessoas trabalham por conta própria e raramente registram as ocorrências de acidentes ${ }^{8,10}$. A real prevalência dos acidentes é subestimada, uma vez que os de menor gravidade não são habitualmente registrados por não implicarem a necessidade de procura de cuidados médicos e de seguro. Foi relatada na região serrana do Rio Grande do Sul a prevalência de acidentes em $10 \%$ dos trabalhadores rurais, e na zona rural de Pelotas, RS, a ocorrência de $11 \%$ de acidentes laborais $4,5,6$.

O objetivo deste estudo foi verificar a ocorrência de acidentes de trabalho no meio rural e determinar o perfil destes trabalhadores.

\section{Material e métodos}

Foram utilizados 60 questionários padronizados para a coleta de dados junto a produtores rurais no Oeste de Santa Catarina. O entrevistado era sempre o proprietário e o executor principal da rotina na propriedade rural. Foram considerados trabalhadores rurais todas as pessoas que atuavam, no mínimo, 15 horas por semana em atividades da agricultura e/ou pecuária, com a finalidade de comercializar e/ou consumir os produtos obtidos.

As variáveis obtidas pelo questionário foram: informações pessoais e demográficas, condições de trabalho e a ocorrência de acidente laboral no ano de 2002. A variável idade foi subdividida em intervalos de 20 anos. Para o número de membros da família, os dados foram agrupados em até 3 membros familiares, de 3 a 5 , de 6 a 9 e um grupo de mais de 9 pessoas.

A escolaridade dos entrevistados era classificada em: fundamental incompleta (até a $4^{a}$ série), fundamental completa, $2^{\circ}$ grau completo e $3^{\circ}$ grau.

O tamanho da propriedade foi classificado em propriedades com menos de 8 hectares e propriedades com mais de 8 hectares, levando-se em conta se a propriedade era particular, arrendada na totalidade ou em parte. 
Tabela 1 Perfil dos trabalhadores rurais do Oeste Catarinense e características da rotina laboral durante o ano de 2002.

\begin{tabular}{|c|c|c|}
\hline Perfil & Total & $\%$ \\
\hline \multicolumn{3}{|l|}{ Estado civil } \\
\hline Solteiro & 17 & 28,3 \\
\hline Casado & 41 & 68,3 \\
\hline Separado & 2 & 3,4 \\
\hline \multicolumn{3}{|l|}{ Idade (anos) } \\
\hline Até 20 & 14 & 23,4 \\
\hline De 21 a 40 & 8 & 13,3 \\
\hline De 41 a 60 & 36 & 60 \\
\hline Mais de 60 & 2 & 3,3 \\
\hline \multicolumn{3}{|l|}{ Anos completos de escola } \\
\hline Fundamental incompleto (até $4^{a}$ série) & 35 & 58,4 \\
\hline Fundamental completo & 23 & 38,3 \\
\hline $2^{\circ}$ grau & 2 & 3,3 \\
\hline $3^{\circ}$ grau & - & - \\
\hline \multicolumn{3}{|l|}{ Exposições ocupacionais } \\
\hline Máquinas e implementos agrícolas & 4 & 6,6 \\
\hline Ferramentas artesanais/manuais & 7 & 11,6 \\
\hline Animais domésticos & 2 & 3,4 \\
\hline Agrotóxicos & 2 & 3,4 \\
\hline Conjunta & 45 & 75 \\
\hline \multicolumn{3}{|l|}{ Jornada semanal de trabalho } \\
\hline Até $48 \mathrm{hs}$ & 12 & 20 \\
\hline Mais de $48 \mathrm{hs}$ & 48 & 80 \\
\hline \multicolumn{3}{|l|}{ Goza férias } \\
\hline Sim & 14 & 24 \\
\hline Não & 46 & 76 \\
\hline
\end{tabular}

O maquinário foi classificado em 3 níveis: maquinário moderno, maquinário artesanal ou a não existência de maquinário.

O item mão-de-obra assalariada foi classificado em: permanente, eventual, não utiliza e/ou vende a mão-de-obra, baseado na necessidade de utilização de força de trabalho suplementar para a rotina laboral.

O trabalho rural foi avaliado através da utilização de máquinas e equipamentos, ferramentas manuais, agrotóxicos, rotina com animais e máquinas, com agrotóxicos e má- quinas, de forma isolada ou conjunta, levando-se em conta se as propriedades são vocacionadas para a agricultura e/ou pecuária.

Na avaliação de eventos estressantes, os itens questionados foram: total de horas da jornada semanal de trabalho e gozo ou não de férias anuais.

As informações sobre a ocorrência de acidentes de trabalho nos últimos 12 meses foram divididas em: acidentes com animal, acidentes com agrotóxicos, com maquinário, 
com ferramentas manuais e/ou artesanais e o número de vezes que ocorreu o evento. Os questionários foram aplicados, após treinamento prévio, por alunos da $2^{\underline{a}}$ e $3^{\underline{a}}$ séries do curso técnico em Agropecuária da Escola Agrotécnica Federal de Concórdia, SC, e que residem na zona rural. Para a tomada de informações, os trabalhadores rurais eram certificados dos objetivos do trabalho, do caráter confidencial das informações e somente incluídos no estudo após seu consentimento verbal.

\section{Resultados}

O perfil dos trabalhadores rurais do Oeste de Santa Catarina e suas características são mostrados na Tabela 1. Na distribuição da faixa etária e estado civil, predominam os chefes de família com idade entre 41 e 60 anos de idade $(60 \%)$ e os casados $(68,3 \%)$. A ocorrência entre 3 a 5 membros familiares constituiu $63,3 \%$, com $23,4 \%$ pertencentes à faixa etária de até 20 anos, $13,3 \%$ com idade entre 20 a 40 anos e 3,3\% de membros familiares com mais de 60 anos.

Para o dado escolaridade, $58,4 \%$ dos trabalhadores rurais cursaram 4 anos, 38,3\% cursaram o ensino fundamental completo, $3,3 \%$ completaram o $2^{\circ}$ grau e nenhum cursou ou cursa o ensino universitário.

O item mão-de-obra assalariada permanente foi de $24 \%, 44 \%$ recorrem à mão-de-obra assalariada eventualmente, $27 \%$ nunca contrataram e $3 \%$ vendem sua mão-de-obra. A jornada semanal de trabalho ultrapassa 48 horas para $80 \%$ dos entrevistados e $24 \%$ relataram gozar férias.

As propriedades rurais com mais de $8 \mathrm{ha}$ correspondem a $83,3 \%$ da amostragem.

A maioria dos trabalhadores rurais (75\%) se envolveu com o conjunto de procedimentos laborais e utilizou na rotina ferramentas manuais e artesanais, implementos agrícolas, agrotóxicos e estiveram expostos a animais domésticos (bovinos, suínos, eqüinos, aves).

O resultado mostrou que 20\% (12) dos 60 produtores rurais entrevistados sofreram acidentes de trabalho, dos quais 2 no trabalho com animais e 10 com ferramentas manuais.

\section{Discussão}

Para efeito de prevenção de acidentes de trabalho é importante que se conheçam os tipos de acidentes, causas e suas prevalências. Os dados são desatual izados e de difícil comparação, pois faltam pesquisas, principalmente as que contemplem produtores rurais.

Os trabalhadores rurais geralmente trabaIham sem carteira assinada, pois são os patrões, e quando acontecem acidentes, estes não se incluem nos dados levantados pelo $\mathrm{INSS}^{4,10}$. A limitação deste estudo está ligada, particularmente, ao fato de se utilizar como instrumento o questionário, que sob a forma de retrospecto, é uma abordagem dependente da memória do entrevistado. Devido à ausência de uma validação específica para a população rural, optou-se por realizar comparação com um estudo na zona rural do $\mathrm{RS}^{6}$. O resultado de 20 acidentes mostrados nesta pesquisa reforça a realidade brasileira, pois os trabalhadores envolvidos em acidentes não procuraram os serviços de saúde e seguro social ${ }^{4,6}$. A dificuldade em serem substituídos em determinadas tarefas laborais é fator determinante para que não busquem assistência médica.

No caso dos acidentes de trabalho relatados nesta investigação a gravidade do evento era mensurada pelo próprio trabalhador, quando definia o seu diagnóstico e tratamento sem buscar auxílio nos serviços de saúde. Esta questão e as de percepção apóiam-se numa avaliação indutiva, interferindo, às vezes, na objetividade, acarretando, com isso, a demora na inversão da condição de saúde. Outro fator sugestivo de maior risco de acidentes de trabalho deve-se ao fato de $80 \%$ dos entrevistados cumprirem jornada de trabalho superior a 48 horas semanais, além de $76 \%$ citarem não gozarem férias. Outra possibilidade está relacionada com fatores de risco psicossociais, como desencadeantes de condição insegura com acidentes. Este alto percentual se relaciona também com a utilização de ferramentas, maquinário e animais durante a rotina laboral.

A natureza da atividade laboral, na qual se utiliza uma variedade grande de equipamentos e procedimentos, reforça a utilização da percepção dos trabalhadores como instrumento adequado na prevenção da ocorrência de acidentes. A diversificação na utilização de equipamentos, maquinários, assim como a exposição a agrotóxicos e animais foi demonstrada em $75 \%$ dos produtores rurais do oeste catarinense, evidenciando que este alto percentual indica maiores chances 
de acidentes laborais, bem como o freqüente uso de ferramentas manuais, em virtude da não mecanização da produção agrícola e pela condição geográfica da região oeste catarinense, com predomínio de terreno declivoso e solo com afloramento de rochas. Além disso, dados de base populacional em regiões desenvolvidas e outras áreas brasileiras necessitam ser conduzidos para que possam ser comparados 5 . Entretanto, há urgência na abordagem de acidentes de trabatho no meio rural subsidiando políticas de saúde pública que sejam capazes de prevenir e reduzir os acidentes laborais em áreas de atividade agropecuária. Na difusão do conhecimento produzido em sala de aula e na prática de rotinas laborais agropecuárias, esta investigação promoveu a avaliação do ambiente de trabalho rural in loco, na medida em que proporcionou a difusão de conhecimento quanto a qualidade de vida no trabalho rural, além de subsidiar futuros estudos na região oeste de Santa Catarina.

\section{Referências bibliográficas}

1. Almeida WF. Trabalho agrícola e na relação com saúde/doença. In: Patologia do trabalho (R. Mendes, org.), Editora Atheneu, Rio de Janeiro, p.487-516, 1995.

2. Conceição PSA, Nascimento IBO, Oliveira PS, Cerqueira MRM. Acidentes de trabalho atendidos em serviço de emergência. Cadernos de Saúde Pública 19(1): 11-117, 2003.

3. De Lucca SR, Favero M. Os acidentes de Trabalho no Brasil: algumas implicações de ordem econômica, social e legal. Revista Brasileira de Saúde Ocupacional 22(81): 7-112, 1994.

4. Faria NMX, Facchini LA, Fassa AG, Tanasi E. Estudo transversal sobre saúde mental de agricultores da Serra Gaúcha (Brasil). Revista de Saúde Pública 33(4): 391-400, 1999.

5. Fehlberg MF, Santos IS, Tomasi E. Prevalência e fatores associados a acidentes de trabalho em zona rural. Revista de Saúde Pública 35(3): 269-275, 2001.

6. Fehlberg MF, Santos IS, Tomasi E. Acidentes de Trabalho na zona rural de Pelotas, Rio Grande do Sul, Brasil: um estudo transversal de base populacional. Cadernos de Saúde Pública 17(6): 13751381, 2001.
7. IBGE (Fundação Instituto Brasileiro de Geografia e Estatística), Censo Agropecuário, IBGE, Rio de Janeiro, 1980

8. Melo RS de. Meio ambiente do trabalho no setor rural. In: Direito do trabalhador rural - Estudos em homenagem a Irani Ferrari, Ed. LTR Ltda, São Paulo, p.205223, 1998.

9. OIT - Organización Internacional del Trabajo. Revista Panamericana de Salud Publica 12(2): 137-139, 2002.

10. Rodrigues UL, Silva JG. Acidentes de trabalho e modernização da agricultura brasileira. Revista Brasileira de Saúde Ocupacional 14(56): 28-39, 1986.

11.Schubert B. Accidentes del trabajo: América del Sur y Central. AISS - Simposio Internacional Global perspective on effective workplace safety strategies. Melbourne, Australia, 15-16 marzo de 2001. 62p.

12.Schubert B. Problemas actuales del seguro obligatorio de accidentes a escala mundial: una muestra de la AISS. Accidentes de trabajo: América del Sur y Central. 27모 Asamblea General de la Asociación Internacional de la Seguridad Social -AISS. Estocolmo, Suecia, 9-15 septiembre de 2001. 26p. 